\title{
Peran Faktor-faktor Psikologis terhadap Depresi pada Pasien Diabetes Mellitus Tipe 2
}

\author{
Jenita DT Donsu ${ }^{1}$ \\ Politeknik Kesehatan Kementerian Kesehatan Yogyakarta \\ M. Noor Rochman Hadjam, Rahmat Hidayat \\ Fakultas Psikologi UGM \\ Ahmad Husain Asdie \\ Fakultas Kedokteran UGM
}

\begin{abstract}
Depression has strong relationship with diabetes mellitus and the aspect of psychology has influence toward the diabetes patient as control. This research aimed to find out the role of psychological factors in dealing with depression suffered by patient of DM-2 and to see the dynamics of both direct and indirect relationship of psychological factors toward the depression of DM-2 patient. The main model is a model that can bring effect of mediation between social support and depression caused by DM-2. Optimism can provide mediating effect of the relationship between social support and self-esteem. Resilience can provide mediating effect of the relationship between social support and self-esteem. Similarly, self-esteem acts as the mediator of the relationship between optimism and resilience toward the depression of DM-2 patient. The result of estimation parameter test showed the direct relationship between social support toward optimism (0.717), resilience (0.811), self-esteem $(0.269)$ and depression $(-0.210)$ and the direct role to depression $(-0.397)$. The higher social support and self-esteem will cause the higher optimism and resilience. On the other hand, the role of self-esteem showed negative coefficient. On the other hand, the role of self-esteem to depression showed a negative coefficient is, the higher self-esteem will be followed by the decrease of depression in patient with DM-2.
\end{abstract}

Keywords: depression, optimism, resilience, self-esteem, social support, DM-2

Abstraks. Depresi berhubungan erat dengan diabetes mellitus, dan aspek psikologis memberikan pengaruh kontrol terhadap diabetes. Penelitian ini bertujuan untuk mengetahui peranan faktor-faktor psikologis serta melihat dinamika hubungan langsung maupun tidak langsung, antara faktor-faktor psikologis terhadap depresi pada pasien DM-2. Model utama merupakan model yang dapat memberikan efek mediasi antara dukungan sosial dan depresi pada DM-2. Optimisme dapat memberikan efek mediasi dari hubungan antara dukungan sosial dan harga diri. Resiliensi mampu memberikan efek mediasi dari hubungan antara dukungan sosial dan harga diri. Demikian juga harga diri berperan sebagai mediator dari hubungan antara optimisme dan resiliensi terhadap depresi pada pasien DM-2. Hasil uji parameter estimasi, terdapat peran langsung antara dukungan sosial terhadap optimisme $(0,717)$, resiliensi $(0,811)$, harga diri $(0,269)$ serta depresi $(-0,210)$ dan peran tidak langsung terhadap depresi $(-0,397)$. Artinya, semakin tinggi dukungan sosial akan semakin optimis dan resilien, serta harga diri makin tinggi pula optimis dan resiliensinya. Pada sisi lain, peran harga diri terhadap depresi menunjukkan koefisien negatif. Semakin tinggi harga diri yang dimiliki penderita DM-2, semakin rendah tingkat depresinya.

Kata kunci: depresi, optimisme, resiliensi, harga diri, dukungan sosial, DM-2

${ }^{1}$ Korespondensi mengenai artikel ini dapat melalui: donsu.tine@gmail.com 
Kesehatan merupakan sesuatu yang sangat berharga, dan yang diharapkan oleh setiap individu dalam menjalani kehidupannya, harapan ini terkadang putus di tengah jalan, karena tanpa disadari berbagai penyakit dapat dialami oleh setiap individu. Seringkali berbagai penyakit kronis maupun akut, dapat menyebabkan kematian. Menurut Sarafino (1998) salah satu penyebab kematian adalah penyakit diabetes mellitus (DM).

Jumlah kasus DM di Amerika bertambah sangat cepat, dan $90 \%$ dari semua kasus tersebut adalah DM tipe-2 (DM-2) dibandingkan dengan DM tipe-1 (DM-1) (Glasgow \& Nutting, 2004; Taylor, 2006). Berdasarkan laporan Diabetes Statistics (2011) di Amerika terdapat sekitar 25,8 juta $(8,3 \%)$ populasi tersebut baik golongan usia remaja dan dewasa, diperkirakan menghabiskan anggaran untuk berobat sebesar 174 milyar dolar Amerika. Berdasarkan jumlah tersebut, terdapat 18,8 juta penduduk yang terdiagnosa dan 7,0 juta penduduk yang tidak terdiagnosa. Diantara jumlah tersebut terdapat 79 juta penduduk dalam status prediabetes. Lebih lanjut dilaporkan bahwa angka kematian akibat diabetes pada tahun 2007 sebesar 231.404 kematian.

International Diabetic Federation (IDF) mengestimasi jumlah penduduk Indonesia usia 20 tahun ke atas, menderita diabetes sebanyak 5,6 juta orang pada tahun 2001, dan meningkat menjadi 8,2 juta orang pada tahun 2020. Survei Departemen Kesehatan (Depkes) RI tahun 2001 terdapat $7,5 \%$ penduduk Jawa dan Bali menderita diabetes. Jumlah penderita DM di dunia termasuk Indonesia diperkirakan meningkat tajam sampai tahun 2020. Terdapat 300 juta atau bertambah tiga kali lipat dari tahun 1994. Atas dasar prevalensi yang bertambah sebesar 1,5\% dari tahun 1994 sehingga berjumlah 2,5 juta, tahun 1998:3,5 juta, tahun 2010:5 juta dan prediksi tahun 2020:6,5 juta terkena DM. Indonesia menempati urutan keempat terbesar untuk jumlah kasus DM dengan prevalensi $8,6 \%$ dari total penduduk setelah India, Cina dan Amerika Serikat (Perkeni, 2006 \& Mubarak, 2008). Survei yang dilakukan oleh Depkes RI menunjukkan bahwa, prevalensi DM sebesar $12,7 \%$ dari seluruh penduduk, dan penyakit ini selalu disertai dengan komplikasi yang diakibatkan adanya gangguan vaskuler (Makmur, 2008; Perkeni, 2006).

Dampak kesehatan di masyarakat menurut hasil penelitian epidemiologi DM di Indonesia menunjukkan angka prevalensi sebesar 1,5-2,3\% pada penduduk berusia lebih dari 15 tahun. Berdasarkan pola pertambahan penduduk saat ini diperkirakan pada tahun 2020 akan ada 3,56 juta pasien DM dengan prevalensi $2 \%$. Peningkatan pendapatan perkapita dan perubahan gaya hidup menyebabkan peningkatan prevalensi penyakit degeneratif seperti penyakit jantung koroner, hipertensi, hiperlipidemia, dan DM (Fisher, Thorpe, McDeVellis, \& DeVellis, 2007; Suyono, 2007). Mangoenprasojo (2005) memperkirakan bahwa sekitar 5 juta penduduk Indonesia menderita DM, yang berarti 1 dari 40 penduduk Indonesia menderita DM.

\section{Komorbiditas Depresi dan Diabetes Mellitus}

Dibandingkan dengan penderita penyakit lainnya, penderita DM berisiko lebih banyak dan jauh lebih besar terhadap gangguan depresi. DM dan depresi mempunyai hubungan sebab akibat. Pertama, depresi akan lebih parah dua kali lipat jika diderita oleh individu dengan DM, dibandingkan dengan penderita lain. Depresi yang diderita oleh penderita penyakit lain selain diabetes hanya mencapai 
11\%-15\% (Kinder, Katon, Ludman, Russo, Simon, \& Lin, 2006).

Kedua, prevalensi depresi mungkin lebih tinggi pada pasien DM yang memiliki komplikasi ganda. Depresi pada pasien DM sering tidak terdeteksi, dan depresi merupakan penghalang utama terhadap manajemen diabetes yang efektif. WFMH (2010) mengestimasi prevalensi dunia pada tahun 2000, terdapat 43 juta pasien DM yang mengalami depresi. Indikasi estimasi bahwa satu diantara empat pasien DM mengalami depresi. Lebih lanjut dikatakan bahwa perkembangan depresi berlipat ganda, bahkan meningkatkan angka kematian sebesar 30\% pada pasien DM.

Ketiga, berkaitan dengan ketidakpatuhan terhadap manajemen diet, olahraga dan obat-obatan serta kontrol HbA1c (Mindy \& Catherine, 2004), maka depresi memperberat beban penyakit (Lype, Shaji, Balakrishnan, \& Varghese, 2009), serta memunculkan lebih banyak gejala fungsional (Clark \& Treisman, 2004). Selain itu, depresi juga dikaitkan dengan tingkat keparahan berupa komplikasi (Lee, Chapa, Kao, Jones, Smith, \& Friedmann, 2009), bahkan kematian pada individu akibat DM, serta berbagai kesulitan hidup lainnya (Glasgow, Toobert, \& Gillette, 2001).

Kesulitan pasien DM dalam mengatasi depresi yang dialaminya, disimpulkan dalam penelitian yang dilakukan oleh Talbot, Nouwen, Gingras, Belanger, dan Audet (1999) tentang cara mengakomodir berbagai gejala, termasuk depresi yang sulit dikendalikan. Depresi merupakan salah satu tekanan yang dapat memperparah diabetes. Menurut Sargyn dan Sargyn (2002) ada hubungan yang signifikan antara depresi dan hiperglikemia pada DM-1 dan DM-2. Akibat yang merugikan dari depresi terhadap DM adalah risiko meningkatnya komplikasi. Di sisi lain hasil studi ini juga menyatakan bahwa apabila manajemen depresi efektif maka gula darah dapat terkontrol. Penelitian yang dilakukan oleh Kinder, dkk. (2006) menunjukkan bahwa pasien DM mempunyai risiko 3 kali lebih banyak mengalami depresi, dan 10 kali lebih banyak menderita penyakit jantung koroner, dibandingkan dengan penyakit lainnya.

\section{Faktor-faktor Psikologis}

Dukungan sosial dapat berpengaruh secara langsung maupun tidak langsung dengan aspek kepribadian. Menurut Coventry, Gilespie, Heat, dan Martin (2004) dan Laudet, Magura, Vogel, dan Knight (2000) dukungan sosial memengaruhi beberapa aspek kepribadian individu, seperti; kepribadian tangguh, harga diri dan rasa optimism (Hames \& Joiner 2012). Dukungan sosial memberikan kontribusi yang besar dalam membantu meningkatkan rasa optimisme seseorang, oleh karena itu dukungan sosial dari orang-orang terdekat diharapkan dapat mengurangi beban psikologis dengan meningkatkan optimism (Keyes, 2002).

Smokowski, Evans, Cotter, dan Webber (2013) menjelaskan optimisme memediasi proses kognitif remaja untuk meningkatkan kesehatan mental. Menurut Weber, Puskar, Faan, dan Ren (2010) dukungan sosial yang memadai dapat memfasilitasi individu untuk lebih optimis dan meningkatkan harga diri. Loh, Schutte, dan Thorsteinsson (2013) dan Weber, Puskar, dan Ren (2010) menambahkan bahwa, optimisme, harga diri dan resiliensi yang tinggi dapat menurunkan depresi seseorang. Artinya, setiap individu memiliki kemampuan berbeda dalam menurunkan depresi yang dialami, namun penelitian di atas menekankan tergantung karakteristik dari masing-masing individu. 


\section{Metode}

Penelitian ini menggunakan metode kuantitatif, melalui proses pengumpulan data dengan cara memberikan sejumlah pertanyaan (Creswell, 1994). Penelitian survei dipilih agar dapat menelaah secara langsung pikiran, pendapat dan perasaan responden serta mendokumentasikan semua ragam yang ada pada sebuah populasi yang berbeda. Menggunakan crosssectional design karena sampel diambil pada satu titik waktu yang sama, juga memberi kemudahan kepada peneliti dalam mendeskripsikan karakteristik sebuah populasi dan temuan-temuan korelasional yang dapat diprediksi (Shaughnessy, Zechmeister, \& Zechmeister, 2006). Subjek berjumlah 248 pasien DM-2, diambil pada beberapa Puskesmas di Kabupaten Sleman. Pengumpulan data menggunakan skala persepsi dukungan sosial, optimisme, resiliensi dan harga diri dengan daya beda lebih besar dari 0,30 dan reliabilitas lebih besar dari 0,871. Teknik analisis statistik yang digunakan adalah persamaan struktural atau Structural Equation Modeling (SEM) dengan bantuan Program AMOS 18. Teknik statistik tersebut digunakan karena pengujian hubungan antar variabel lebih kompleks dan simultan (Maruyama, 1998).

\section{H a s i 1}

Berdasarkan Tabel 1, sebagian besar pasien DM-2 berada pada kategori sedang, memiliki tingkat optimisme $(41,5 \%)$, resiliensi $(54,8 \%)$, harga diri $(54,0 \%)$, dukungan sosial $(55,2 \%)$ dan depresi $(44,4 \%)$. Umumnya faktor-faktor psikologis yang diukur berada dalam kategori sedang, selebihnya adalah tinggi dan sangat tinggi serta rendah dan sangat rendah. Artinya, sebagian besar penderita DM-2 dalam penelitian ini memiliki rasa optimis, resiliensi, harga diri, dukungan sosial, dan depresi dalam kategori sedang. Kategori ini tidak menggambarkan suatu kondisi yang baik atau buruk, namun biasa-biasa saja dan masih dapat menjalani kehidupan serta memandangnya dengan harapan positif untuk kesembuhan penyakit yang dideritanya.

Berdasarkan Gambar 1, sebagian besar indeks-indeks tersebut menunjukkan RMSEA sudah sesuai dengan kriteria. Walaupun indeks AGFI masih berada di bawah kriteria $(0,888 \leq 0,90)$, namun secara keseluruhan sudah memenuhi kriteria goodness of fit maka disimpulkan model tersebut sudah fit.

Selain indikator tersebut, ada indikator Akaike Information Criterion (AIC) yang ditemukan sebesar 266,456 pada default model dan 272,000 pada saturated model.

Tabel 1

Distribusi Frekuensi Variabel Penelitian

\begin{tabular}{lccccc}
\hline Kategori & $\begin{array}{c}\text { Depresi } \\
\mathbf{( \% )}\end{array}$ & $\begin{array}{c}\text { Optimisme } \\
\mathbf{( \% )}\end{array}$ & $\begin{array}{c}\text { Resiliensi } \\
\mathbf{( \% )}\end{array}$ & $\begin{array}{c}\text { Harga diri } \\
\mathbf{( \% )}\end{array}$ & $\begin{array}{c}\text { Duksos } \\
\mathbf{( \% )}\end{array}$ \\
\hline Sangat Tinggi & $18(7,3)$ & - & - & $3(1,2)$ & - \\
Tinggi & $54(21,8)$ & $80(32,3)$ & $52(21,0)$ & $57(23,0)$ & $74(29,8)$ \\
Sedang & $110(44,4)$ & $103(41,5)$ & $136(54,8)$ & $134(54,0)$ & $137(55,2)$ \\
Rendah & $66(26,6)$ & $55(22,2)$ & $42(16,9)$ & $40(16,1)$ & $18(7,3)$ \\
Sangat Rendah & - & $10(4,0)$ & $18(7,3)$ & $14(5,6)$ & $19(7,7)$ \\
\hline
\end{tabular}




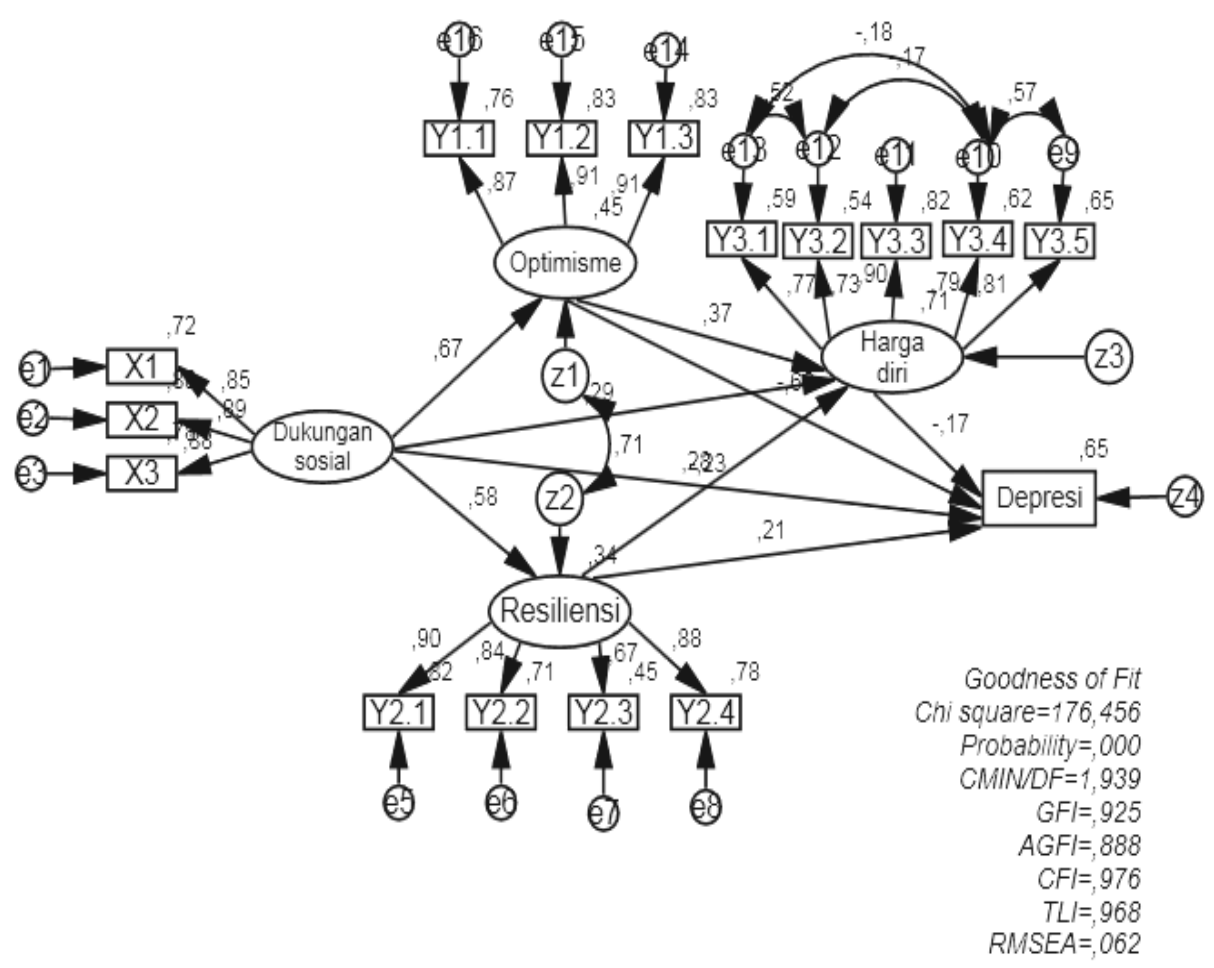

Gambar 1. Hasil Uji Model

Artinya, model telah fit karena AIC default model lebih kecil dari saturated model. Demikian juga dengan indikator Expected Cross-Validation Index (ECVI) sebesar 1,079 pada default model dan 1,101 pada saturated model. Menurut Ghozali (2009) tambahan kriteria fit model jika pada indikator AIC dan ECVI ditemukan nilai default model lebih kecil dari saturated model.

\section{Diskusi}

Hasil penelitian ini mendukung beberapa penelitian sebelumnya yang dilakukan oleh Song, Han, Park, Nam, dan Kim (2012) bahwa dukungan sosial dianggap sebagai faktor utama memengaruhi kesehatan, yaitu memengaruhi kemampuan individu beradaptasi dalam perawatan diri pada pasien DM. Perlunya peningkatan kesadaran akan persepsi dukungan sosial terhadap pengelolaan penyakit kronis seperti diabetes. Penerimaan per- sepsi dukungan sosial dalam jangka panjang dapat mengurangi kesenjangan masalah peningkatan glukosa pada pasien DM.

Dukungan sosial dan kesehatan fisik berhubungan dengan depresi. Menurut Fortman (2010) serta Nemato, Bödeker, dan Iwamoto (2011) depresi pada penderita diabetes terkait dengan kesehatan fisik yang buruk. Lebih lanjut dikatakan, dukungan sosial dan diabetes memerlukan penyelesaian dengan langkah-langkah yang lebih serius. Hasil analisis menunjukkan bahwa, pengaruh dukungan sosial pada individu dengan diabetes, berhubungan dengan gejala diabetes yang dikeluhkan. Individu dengan DM-2 yang mengalami komorbiditas depresi, mengelola diabetes kurang efektif bila dukungan sosial kurang maksimal, sehingga kurang adanya kepuasan hidup serta harapan tentang masa depan dibandingkan dengan individu yang tidak depresi. Huang, Costeines, Kaufman, dan Ayala (2013) 
menambahkan dukungan sosial yang dirasakan rendah berhubungan dengan tingkat depresi ibu yang berkepanjangan, menyebabkan keterlambatan dalam perkembangan bayi.

Penulis juga mendukung hasil penelitian Ames, Rawana, dan Gentile (2013) bahwa, harga diri dan optimisme memberikan efek mediasi terhadap hubungan antara penggunaan alkohol dan gejala depresi. Pentingnya untuk mempromosikan harga diri dan optimisme guna mencapai kesehatan mental yang optimal. Artinya, variabel harga diri dan optimisme cukup berperan dalam melindungi individu terhadap berkembangnya depresi.

\section{Uji Hipotesis}

Tabel 2 menunjukkan dukungan sosial berperan langsung terhadap optimisme, resiliensi dan harga diri. Selanjutnya hasil uji terhadap parameter estimasi menunjukkan adanya peran langsung dukungan sosial terhadap masing-masing variabel, yaitu; optimisme $(0,717)$; resiliensi $(0,811)$; dan harga diri $(0,269)$; serta depresi $(-0,210)$; dan pengaruh tidak langsung terhadap depresi $(-0,397)$. Nilai critical ratio (CR) dari masing-masing variabel yaitu; optimisme $(10,539)$; resiliensi $(8,927)$; harga diri $(4,455)$; dan depresi $(-3,477)$.
Berdasarkan nilai $\mathrm{CR}$ tersebut, menunjukkan $p<0,05$ atau $C R>1,96$ sehingga dapat disimpulkan, hipotesis diterima.

Persepsi dukungan sosial, optimisme, resiliensi, dan harga diri berpengaruh signifikan terhadap depresi. Hal ini menunjukkan bahwa, terdapat pengaruh langsung dan tidak langsung dukungan sosial terhadap optimisme, resiliensi, harga diri dan depresi. Pengaruh langsung antara persepsi dukungan sosial terhadap optimisme, resiliensi, dan harga diri menunjukkan koefisien positif, sedangkan koefisien persepsi dukungan sosial terhadap depresi adalah negatif. Artinya, persepsi dukungan sosial yang semakin meningkat akan diikuti dengan semakin tingginya optimisme, resiliensi, dan harga diri pada pasien DM-2, sedangkan persepsi dukungan sosial terhadap depresi memiliki koefisien estimasi negatif yang menunjukkan, semakin besar persepsi dukungan sosial, akan semakin menurun depresi yang dialami pasien DM-2.

\section{Kesimpulan}

Hipotesis diterima dengan hasil uji parameter estimasi, terdapat peran langsung antara dukungan sosial terhadap variabel optimisme, resiliensi, harga diri

Tabel 2

Hasil Pengujian Hipotesis

\begin{tabular}{llcccc}
\hline No & Variabel bebas & Variabel & CR & \multicolumn{2}{c}{ Effect } \\
\cline { 5 - 6 } & & terikat & & Direct & Indirect \\
\hline $\mathbf{1}$ & Dukungan sosial & Optimisme & $10,539^{* * *}$ & 0,717 & - \\
$\mathbf{2}$ & Dukungan sosial & Resiliensi & $8,927^{* * *}$ & 0,811 & - \\
$\mathbf{3}$ & Dukungan sosial & Harga diri & $4,455^{* * *}$ & 0,269 & - \\
$\mathbf{4}$ & Dukungan sosial & Depresi & $-3,477^{* * *}$ & $-0,210$ & $-0,397$ \\
$\mathbf{5}$ & Optimisme & Harga diri & $3,642^{* * *}$ & 0,315 & - \\
$\mathbf{6}$ & Optimisme & Depresi & $-6,385^{* * *}$ & $-0,560$ & $-0,054$ \\
$\mathbf{7}$ & Resiliensi & Harga diri & $3,148^{* * *}$ & 0,186 & - \\
$\mathbf{8}$ & Resiliensi & Depresi & $2,425^{* *}$ & 0,141 & $-0,032$ \\
$\mathbf{9}$ & Harga diri & Depresi & $-1,911^{*}$ & $-0,170$ & - \\
\hline
\end{tabular}

${ }^{* * *}$ signifikan pada level 1\%; ${ }^{* *}$ signifikan pada level 5\%; ${ }^{*}$ signifikan pada level 10\% 
serta depresi dan peran tidak langsung terhadap depresi. Demikian juga memenuhi nilai $C R>1,96$. untuk masing-masing variabel optimisme, resiliensi, harga diri, dan depresi. Artinya, terdapat peran dukungan sosial terhadap optimisme, resiliensi dan harga diri serta menunjukkan koefisien estimasi positif, yaitu semakin tinggi dukungan sosial, akan semakin optimis dan resilien pasien DM-2. Peran harga diri terhadap depresi menunjukkan koefisien negatif yaitu, semakin tinggi harga diri akan diikuti dengan semakin menurunnya depresi pada pasien DM-2.

Karakteristik subjek menunjukkan jenis kelamin perempuan lebih banyak dari pada laki-laki, lama menderita DM-2 lebih besar dari 12 tahun dan subjek mengalami komplikasi lebih banyak daripada tanpa komplikasi. Berdasarkan distribusi frekuensi semua variabel penelitian menunjukkan kategori sedang. Dukungan sosial tinggi secara langsung dapat meningkatkan optimisme, resiliensi, serta harga diri, dan tidak langsung dapat meningkatkan harga diri serta menurunkan depresi pasien DM-2. Gabungan ilmu bidang kesehatan dan psikologi dalam penelitian ini menunjukkan peranan faktor-faktor psikologis sebagai mediator, dapat dikembangkan pada aspek kepribadian terhadap kasus-kasus terminal lainnya (kanker dan gangguan kardiovaskuler).

Kasus-kasus terminal di Puskesmas maupun di rumah sakit perlu mendapat penanganan secara sinergis melalui lintas disiplin ilmu (kesehatan dan psikologi), sehingga pasien memperoleh penanganan fisik juga psikologis, karena terbukti faktor-faktor psikologis dapat memberikan efek mediasi terhadap penurunan depresi pada pasien DM-2. Dinamika hubungan langsung maupun tidak langsung antara faktor-faktor psikologis yaitu: dukungan sosial, optimisme, resiliensi, dan harga diri, terhadap depresi pada pasien DM-2, dapat dikembangkan pada penelitian dalam skala yang lebih luas, baik sampel maupun lokasi agar dapat digeneralisasi, serta menggunakan perangkat lunak yang mampu mengakomodir lebih banyak variabel penelitian. Hasil uji model telah memenuhi kriteria kesesuaian (goodness of fit) sehingga dapat digunakan sebagai model untuk penelitian selanjutnya.

\section{Kepustakaan}

Ames, M. E., Rawana, J. S., \& Gentile, P. (2013) The protective role of optimism and self-esteem on depressive symptom pathways among Canadian Aboriginal youth. Journal of Youth and Adolescence. Advance Online Publication. doi: 10.1007/s10964-013-0016-4.

Conventry, W. L., Gilespie, N. A., Heat, A. C., \& Martin, N. G. (2004). Perceived social support in a large community. Age and sex different original pape. Social Psychiatry Epidemiology, 34, 625636.

Clark, M. L., \& Treisman, G. J. (2004). Pain and Depression. New York: Printed in Switzerland.

Creswell, J. W. (1994). Research design: Qualitative $\mathcal{E}$ quantitative approaches. London: Sage Publication.

Diabetes Statistics. (2011). The 2011 National Diabetes Fact Sheet. Diunduh dari: http://www.diabetes. org/diabetes basics/diabetes-statistic

Fisher, E. B., Thorpe, C. T., DeVellis, B. Mc., \& DeVellis, R. F. (2007). Healthy coping, negative emotions, and diabetes management: A systematic review and appraisal. The Diabetes Educator, 33, 1080-1095. 
Fortmann, A., Gallo, L. C., Walker, C., \& Tsimikas, P. A. (2010). Support for disease management, depression, selfcare, and clinical indicators among Hispanics with type 2 diabetes in San Diego County, United States of America. Rev Panam Salud Publica, 28(3), 230-234.

Ghozali, I. (2009). Aplikasi Analisis Multivariate dengan Program SPSS. Semarang: BP Universitas Diponegoro

Glasgow, R. E., Toobert, D. J., \& Gillette, D. (2001). Psychological barriers to diabetes self-management and quality of life. Diabetes Spectrum, 14(1), 33-41.

Glasgow, R. E., \& Nutting, P. A. (2004). Diabetes. Dalam Haas, L.J. (Ed). Handbook of primary care psychology. New York: Oxford University Press, Inc.

Hames, J. L., \& Joiner, T. E. (2012). Resiliency factors may differ as a function of self-esteem level: Testing the efficacy of two types of positive self-statements following a laboratory stressor. Journal of Social and Clinical Psychology, 31, 6, 641-662.

Huang, C. Y., Costeines, J., Kaufman, J. S., \& Ayala, C. (2013). Parenting stress, social support, and depression for ethnic minority adolescent mothers: Impact on child development. Journal Child Family Study, 10, 1007-1015.

Keyes, C. L. M. (2002). The menthal health continuum: From languishing flourishing in life. Journal of Health and Social Behaviour. Albany, 43, 2, 207-222.

Kinder, L.S., Katon, W.J. Ludman, E., Russo, J., Simon, G., Lin, E.H.B. (2006). Improving depression care in patients with diabetes and multiple complications. Journal General Medic, 21, 10361041.

Laudet, A., Magura, S., Vogel, H., \& Knight, E. (2000). Support, mutual aid and recovery from dual diagnosis. Community Mental Health Journal, 36, 457-476.

Lee, H. J., Chapa, D., Kao, C. W., Jones, D., Smith, J., \& Friedmann, E. (2009). Depression, quality of life, and glycemic control in individuals with type 2 Diabetes, Journal of American Academy of Nurse Practitioners, 8(5), 214224.

Loh, J. M. I., Schutte, N. S., \& Thorsteinsson, E. B. (2013). Be happy: The role of resilience between characteristic affect and symptoms of depression. Journal Happiness Study, 13, 9469-9679.

Lype, T., Shaji, S. K., Balakrishnan, A., \& Varghese, D. C. (2009). Cognition in type 2 diabetes: Association with vascular risk factors, complications of diabetes and depression, Original Article, Annals of Indian Academy of Neurology, 25-27

Makmur, (2008). Lansia Peroleh JSLU Tahun 2008. Diunduh dari: Lintas-Daerah. Com tanggal 19 March 2010.

Mangoenprasodjo, A. S. (2005). Hidup Sehat dan Normal dengan Diabetes. Yogyakarta: Thinkfresh.

Maruyama, G. M. (1998). Basic of Structural Equation Modeling. London: Sage Publication.

Mindy, T., \& Catherine, S. (2004). Diabetes management: Glycated hemoglobin testing $(\mathrm{HbA1c})$. Bulletin State of Alaska Epidemiology, 3, 15.

Mubarak, H. (2008). Diabetes Mellitus Tipe2, Diunduh dari: SupportLineBreakNewLine.htm. tanggal 25 Maret 2010.

Nemoto, T., Bödeker, B., \& Iwamoto, M. (2011). Social support, exposure to violence and transphobia, and corre- 
lates of depression among male-tofemale transgender women with a history of sex work. American Journal of Public Health, 101(10), 1980-1990.

Perkumpulan Endokrinologi Indonesia (Perkeni). (2006). Konsensus pengelolaan dan pencegahan diabetes mellitus tipe 2 di Indonesia.

Sarafino, E. P. (1998). Health Psychology: Biopsychosocial Intervention, Third Edition, New York Willey \& Sons. Inc.

Sargyn, H., \& Sargyn, M. (2002). Diabetes and Depression. Journal of Endocrinology and Metabolism, 3, 95-100.

Shaughnessy, J. J., Zechmeister, E. B., \& Zechmeister, J. S. (2006). Research Methods in Psychology. Yew York: The McGraw Hill Companiens, Inc.

Smokowski, P. R., Evans, C. B. R., Cotter, K. I., \& Webber, K. C. (2013). Ethnic identity and mental health in American India youth: Examining mediation pathways through selfesteem, and future optimisme. Journal Youth Adolescence, 013, 992-997.

Song, Y., Han, H. R., Park, S. Y., Nam, S., \& Kim, T. (2012). Unmet needs for social support and effects on diabetes selfcare activities in Korean Americans with type 2 diabetes. The Diabetes Educator, 38, 77-85.

Suyono, S. (2007). Kecenderungan peningkatan jumlah penyandan diabetes. Dalam Soegondo, S., Soewondo, P., \& Subekti, I. (Ed). Penatalaksanaan Diabetes Melitus Terpadu. Jakarta: Pusat Diabetes dan Lipid RSUP Nasional Dr. Cipto Mangunkusumo, Fakultas Kedokteran Universitas Indonesia, bekerjasama dengan Departemen Kesehatan RI dan WHO.

Talbot, F., Nouwen, A., Gingras, J., Belanger, A., \& Audet, J. (1999). Relations of diabetes intrusiveness and personal control to symptoms of depression among adulth with diabetes. Health Psychology, 18(5), 537-542.

Taylor, S. E. (2006). Health Psychology, Sixth Edition. Inc. Singapore: Mc Graw Hill.

Weber, S., Puskar, K. S., \& Ren, D. (2010). Relationships between depressive symptoms and perceived social support, self-esteem, \& optimism in a sample of rural adolescents. Issues in Mental Health Nursing, 31, 584-588.

World Federation for Mental Health (WFMH). (2010). Mental Health Chronic Physical Illness. 